\title{
Escrevendo Cartas. Jesuítas, Escrita e Missão no Século XVI
}

Fernando Torres Londoño*

PUC-SP

\section{Resum o}

Este artigo examina a produção e troca de correspon dência entre os missionários jesuítas do século XVI e seus superiores, resgatando o texto inaciano construído gradualmentenessa circulação de cartas entre Europa,Ásia eAmérica. N esse texto, recuperado nosExerć́cios Espirituais, nas Constituições e nas cartas do santo, estariam as bases da definição de um método missionário para a redução do infiel à Fé católica.

Palavras-chave: jesuítas; missões; cartas.

\section{ABSTRACT}

This article deals with the making and exchange of letters between the Jesuit missionaries and their superiors in the sixteenth century. These letters circulating in Europe, Asia and America are based on Saint I gnacyo's writings, mainly the Spiritual Exercices, the Constitutions and his own letters. They are the bases of themissionary method for theconvertion of the unfaithful to the Catholic religion. Keywords: jesuits; mission; letters.

Somente darey conta aV.R. de nossa chegada a esta terra e do que nella fizemos e esperamos fazer em ho Senhor Nosso, deixando os fervores de nossa prospera viagem aos I rmãos que mais em particular a notaram

Serafim Leite

\section{INTRODUÇÃO}

Assim começou o padre Nóbrega, provavelmente a 10 de abril de 1549, na Bahia, sua primeira carta como missionário, ao superior em Portugal,padreSimão Rodrigues. Nóbrega tinha chegado em 29 de março, na armada de Toméde Sousa, primeiro governador geral do Brasil. M enos de quinze dias se tinham passado e o superior da pequena missão que se iniciava já escrevia para seu superior contando-Ihe como tinha sido recebido, onde estavam alojados, o que tinham encontrado na terra, o estado de pecado e abandono moral em que viviam os portugueses, os primeiros contatos com os índios e 0 
interesse que mostravam em adotar a fé, os avanços na comunicação com estes e os planos de catequese e de ir a outras regiões como Pernambuco (Leite, 1954, vol I, pp.109-115). Como ele, os outros padres eirmãos também escreveram para Portugal e hoje contamos com três grossos volumes de cartas dos primeiros jesuítas entre 1549 e 1563.

Até a expulsão da Companhia, no Brasil e no Pará-M aranhão, superiores, padres e irmãos não deixaram de escrever cartas, informes, relatórios e crônicas em quese recolheu a vida e o cotidiano da Companhia nas colônias portuguesas da América' ${ }^{1}$. Suas cartas foram se acumulando em diversas casas de governo e hoje se encontram nos arquivos de Roma, Lisboa, Évora, Rio de Janeiro e Madrid².

Esse acervo, mesmo espalhado, se constituiu na referência para a recuperação do passado dos jesuítas no Brasil e da construção de sua memória. Esta recuperação passou a ser feita depois da restauração, na segunda metade do XIX. No caso do Brasil, o padre Serafim Leite, consciente da importância destas cartas e do imaginário que elas al imentavam a respeito da Companhia nos primeiros anos da colonização lusa no Brasil, além de utilizá-las para a redação de sua História da Companhia de Jesus no Brasil, continuou o trabaIho já iniciado por historiadores leigos do IH GB, como Capistrano de Abreu, 12 que desde 1885 se tinha empenhado em localizar e publicar cartas dos padres Nóbrega e Anchieta ${ }^{3}$. Trabalhando nos arquivos da Companhia em Roma, Portugal e Espanha e em diversas províncias, padre Leite localizou cartas perdidas, verificou datas, autores e destinatários, transcreveu e posteriormente publico u as cartas dos primeiros anos da presença jesuítica no Brasil ${ }^{4}$. A publicação destas coletâneas disponi bilizou para estudiosos e historiadores um riquíssimo material seriado para a pesquisa, que nos últimos anos tem sido utilizado para a elaboração de IC, mestrados e doutorados so bre diversos aspectos, e em particular sobre o processo de cristianização e as missões 5 .

Nos anos setenta, José Carlos Sebe Bom M eihy advertiu sobre a presença de cartas edificantes e de informação entre a volumosa correspondência je suítica 6 . Assim, desde o começo da missão dos inacianos no Brasil, uma boa parte das cartas teria sido produzida com o propósito claro de edificar, na expressão ascética da épo ca, que apontava para as ações que serviam para manifestar a presença divina, estimular a Fé do próximo e infundir piedade. ${ }^{7}$. As cartas estavam determinadas pela sua função, seus destinatários e objetivos particulares. Em comunicação de 1997 no Congresso de Americanistas em Q uito, inseri a questão da utilização das cartas e das crônicas dos jesuítas na América, dentro da referência básica do carisma inaciano e de sua gestação no século XVI. Coincidi assim com o apontado por Leandro Karnal, Paulo Assunção e Julio Quevedo em suas teses e dissertações ${ }^{8}$. 
Pelo seu traço de orientação de tudo a um "princípio e fundamento", a espiritualidade inaciana colocava todas as ações do indivíduo a serviço de Deus. Era na expectativa de Santo I gnácio pela procura da vontade de Deus que se dirigia a vida de cada jesuíta. Para isto, particularmente nas Consti tui ções da ordem e nas suas cartas, o fundador foi desdobrando as instruções para seguir o método apresentado nos Exercícios Espi rituais. Quando os padres e irmãos começaram a se comunicar por cartas desde as mais variadas partes do globo, este espírito inundava sua escrita nas expressões, nos assuntos e epi sódios referidos. Ao escrever sobre sua missão, os jesuítas o faziam utilizando um registro ou tom inspirado na subjetividade de sua vivência do carisma inaciano.

Como historiador, acredito que não consigo ouvir esse registro subjetivo considerando referências e maneiras de escrever só como edificantes.Da mesma forma, as informações presentes nas cartas não se deviam unicamente ao espírito de controle ou ao desejo de matar curiosidades (Assunção, 2000, pp. 81-89). Elas seriam recolhidas e enviadas à Europa constituindo textos diferenciados, produzidos como parte de um projeto missionário queestava sendo construído e para o qual o poder sempre foi uma referência fundamental. E nessa construção da missão, a escrita cumpriu um papel estratégico.

Formando parte de um projeto em andamento, apresento aqui alguns elementos referentes ao contexto jesuítico e do próprio I gnácio de Loyola, que explicam a importância estratégica da correspondência e o privilégio da escrita entre os jesuítas como meio de comunicação. A partir daí e compulsando documentos da ordem do século XVI, aponto para a importância que esta correspondência teve para construir um imaginário sobreas M issões da Companhia que as fizesse presentes na Europa. Faço isto sabendo que estou triIhando terreno pantanoso para um historiador, como o da espiritualidade, mas acredito que explicitar ponderações de método sobre o tratamento da documentação religiosa pode ser útil para o futuro da pesquisa do catolicismo entre nós.

\section{As cartas e a visibilidade da "universal Companhia"}

A Companhia de Jesus nasceu e se estendeu no século XVI a quatro continentes sob o domínio da escrita. No momento em que a primeira dúzia de "companheiros" se colocou a serviço do papa, compreendeu-se que a dispersão poderia ameaçar sua união e para se manterem unidos em Jesus Cristo nasceu o Instituto. Nas Constituições cuidou Santo I nácio de dedicar uma das dez partes, a oitava, a "De lo que ayuda para unir los repartidos com su cabeza entre sí" ${ }^{\prime}$. No primeiro número dessa parte colocou que pela dificuldade 
de união dos membros com a cabeça e por estarem espal hados entre fiéis e infiéis deveriam contar com diversas ajudas,

(...) pues no conservarse puede ni regirse, ni por consiguiente conseguir el fin que pretiende la Compañia a mayor gloria divina sin estar entre si y com su cabeza unidos los miembros della (Loyola, 1963, p. 556, número 655).

O vínculo entre súditos esuperiores através da obediência (número 659), o incentivo do "espírito de corpo", a uniformidade de vida e doutrina e o combate às divisões (números 663-665 e 671-672), a chamada "união dos ânimos" e a comunicação permanente através de cartas (números 662 e 673-676), foram prescritos por Loyola como respostas ao desafio da dispersão e da "diversidad que no dañe a la unión" (Loyola, 1963, pp. 561-563). Importava assim, neste momento, estabelecer os canais e formas de comunicação da Companhia, das corriqueiras às mais complexas, como a que passava pela convocação da Congregação Geral. Inter essava, em particular, cuidar da circulação de informações pessoalmente ou por "letras" ( número 679).

No que diz respeito às "letras missivas", determinaram-se obrigações em dois sentidos: entre súditos e superiores e entre casas e províncias. No primeiro sentido, o padre geral e os provinciais deveriam saber e"entender las nuevas e informaciones que de unas y otras partes vienen" (número 673). Para garantir que as cartas fossem realmente enviadas, os superiores deveriam escrever para os provinciais cada semana e estes responderiam e escreveriam também ao padre geral a cada mês. (número 674). Ainda para

(...) mas información de todos se imbíe cada cuatros meses al provincial, decada casa y colegio una lista breve duplicada de todos los que hay en la tal casa, y los que faltan por muerte o por otra causa" (número 676).

No segundo sentido, o governo central ou provincial deveria ordenar "como em cada parte se pueda saber de las otras lo que es para consolación y edificación mutua em el Señor"( número 673). Para isto os superiores escreveriam ao provincial a cada "quatro meses uma letra que contenga solamente las cosas de edificación em la lengua vulgar de la província y outra em latín del mismo tenor"( número 675). Ambas deveriam ir duplicadas para que uma fosse mandada ao geral e da outra se fizessem cópias "tantas veces, que baste para dar noticia a los otros de su Provincia" (número 675). Para ganhar tempo e garantir que as notícias circulariam, os superiores poderiam escrever diretamente ao general,mandando cópia ao provincial e ainda avisando "a los demas de su província,imbiándoles copias de las que escriben al provincial"(número 675).

Foi traçado assim, nas Constituições, um conjunto de operações de co- 
municação que compunha um sistema de informações. N este sistema se estabeleciam responsabilidades para a ger ação das informações e destinatários destas. Foram fixados prazos, determinada a produção de cópias, definida a circulação destas, consideradas as línguas e apontados os temas a serem tratados nas cartas. Coerente com o entendimento hierárquico de Loyola, a comunicação deveria existir de forma vertical para o governo e horizontal para a união dos ânimos. Para conseguir este último, nas condições do século XVI, se recorria à duplicação, assim

(...) dara orden el general que de las letras que se imbián de las províncias,se hagan tantas copias, que basten para proveer a todos los otros provinciales" (número 675).

Sendo a diversidade lingüística um obstáculo, se utilizava o latim, mantendo as línguas ditas "vulgares" na articulação jesuítica do universal e do particular. Tudo isto para garantir a função das cartas: consolar e edificar, dando a conhecer as obras feitas em nome de Deus, "Para que lo de uma província se sepa em outra" (675). Escrever para que outros lessem, copiassem, difundissem e guardassem. Assim, na parte terceira das Constituições sobre a formação dos jovens jesuítas, ao tratar das refeições, se manda ler algum livro piedoso ou "cosas semejantes son como leer letras de edificación" (Loyola, 1963, 470).

Acredito que este sistema de informações atuava como suportepara um sistema de decisões nitidamente inaciano: hierárquico e vertical. Informar a partir da base nas cartas periódicas. Reunir registros eintercambiar opiniões à procura de uma decisão. Comunicar por escrito a decisão a partir do governo geral. Acatar e executar a decisão nas instâncias. Embora fosse possível re presentar, em várias ocasiões, a obediência, particularmente o entendimento desta se deveria impor ${ }^{10}$. Tal sistema de informações permitiu pelo menos a procura de al guma uniformidade das políticas numa infinidade de ações às vezes discordantes. Este sistema foi central na ordem e se gestou a partir do próprio percurso letrado do fundador e do relevo concedido às letras na Companhia de esus como se verá em seguida.

\section{ESCRITA E AÇÃO EM INÁCIO DE LOYOLA}

A Companhia de esus começou a ser gestada em Paris, a partir de 1531, e seu núcleo inicial foi um grupo de estudantes do Colégio deSanta Bárbara que se reunia em torno de um basco quetinha fama dehomem santo. Incluindo o próprio Loyola, os primeiros jesuítas eram todos mestres em letras. Nas 
ger ações seguintes já estariam presentes também os doutores. Os chamados primeiros companheiros valorizaram desde o início os aspectos relacionados com as letras, o que compreendia escrever e ler em vernáculo e em latim, ter conhecimento de outras línguas e de textos existentes em grego e latim. Assim, obrigações comuns aos padres de maior grau, os chamados professos, como o de viver de esmolas, não se aplicava aos jovens que deveriam dedicarse ao estudo. Para isto, se buscou doações e proteções que foram constituindo um patrimônio destinado a ser investido na formação dos jovens. Uma ordem descentralizada mas ao mesmo tempo hierárquica como a Companhia de Jesus só podia ser letrada no século XVI ${ }^{11}$.

Porém o fato de se tratar de uma ordem de letrados não explica suficientemente uma força de expansão tão grande. Esta capacidade de crescer rápido teria sim que ver com o entendimento dado pelos primeiros jesuítas ao registro escrito como expressão de uma práxis colocada ao serviço da procura da vontade divina. Aqui como em outras partes real ço a figura de I gnácio de Loyola.

A memória jesuítica fixou a imagem de Santo I gnácio de Loyola como o homem da ação. A presenta-se aqui outro traço que considero essencial: Loyola foi também um homem da escrita. Embora isso reduza sua rica personalidade,é difícil não ser levado em consideração para quem entre 1524-1556 escreveu seis mil oitocentas e quinze cartas $^{12}$. Desde sua convalescença na cidade de Loyola, pelo ferimento recebido em Pamplona, se sabe pelo próprio santo que a escrita o acompanhou nas suas primeiras experiências espirituais, quando escrevia num caderno palavras de Cristo e Nossa Senhora utilizando tintas de diferentes cores para cada um e com "buena letra porque era muy buen escribano" (Loyola, 1963, p. 93) , como lembrou ao padre Gonzalez de Camara sem nenhuma modéstia. Na sua auto biografia ele fala também que em M anresa, onde começou propriamente sua experiência espiritual, colocou seus pecados por escrito, e segundo o padre I parraguirre, descrevia práticas espirituais num caderno de notas. (Loyola, 1963,181). A proximadamente dez anos depois,estes primeiros registros eram já o livro dos Exercícios Espirituais (Loyola, 1963, p.196). Em matéria de ascética e mística, Loyola ainda produziu o Diário Espiritual (Loyola, 1963, p. 318), uma minuciosa descrição dos estados de sua alma durante um processo de oração entre 1544 e 1545, para tomar uma decisão a respeito da pobreza nas casas professas da nascente Companhia. De forma mais aprimorada foram registrados aqui estados espirituais e sensações vivenciadas e lidas por Loyola na procura de sinais da vontade divina. Este vínculo entre escrita e devoção o acompanhou até o fim de sua vida, quando escrevendo as Constituições "cada dia escribia lo que pasaba por su alma" (Loyola, 1963, p. 159).

Até as vésper as da fundação da Companhia de Jesus,I ñigo acrescentou à sua cultura letrada os estudos de artes e teologia em Paris, e principalmente 
escreveu cartas às mais variadas pessoas definindo assim um traço de sua atividade epistolar. Primeiro como I ñigo e depois como o padre I gnácio, Loyola escreveu a diversas pessoas preeminentes entre el as o papa, o imperador CarlosV, reis, rainhas, nobres, doutores,e também pessoas de condição mais simples como religiosos, clérigos e as chamadas pessoas espirituais $s^{13}$. Este traço é importante porque Loyola transitava entre tratamentos, etiquetas e estilos bem diferentes de forma fluida. A todas essas pessoas Loyola se dirigiu com um intuito, mesmo que fosse tão simplório como informá-las de que rezava por elas ${ }^{14}$. A consciência das expectativas do interlocutor e dos objetivos do redator, o superior geral quis passar para seus companheiros que não tinham sua mesma experiência e história. Assim, escrevendo ao padre Berze, em $24 / 2 / 1554$, recomendava que quando se escrevesse para pessoas de muita qualidade e intel igência de fora da Companhia "se detenga menos el que escribe en las cosas que particolarmente tocan a personas de la Compañia, extendiendose mas en las generales". (Loyola, 1963, p.854).

Escrever era para Loyola um ato comandado por um sentido. Ele escreveu os Exercícios Espirituais para ensinar e acompanhar, as Constituições para regulamentar, as Instruções aos membros da Companhia para manter a união, seus diários para entender sua própria espiritualidade, e as cartas como forma de agir e comunicar sobre os mais variados assuntos e situações. Loyola acreditava na comunicação como forma privilegiada de ação, e se seguirmos a Barthes no seu ensai o sobre os Exercícios Espirituais onde identificou quatro textos, podemos dizer que nas cartas do santo coexistiam vários textose vários destinatários ${ }^{15}$. Em tempos de conflito ou de perseguições, como as acontecidas quando estudante, recorreu à escrita para se defender, argüindo, refutando. Quando já havia se tornado influente escrevia para convencer, definir, decidir, reclamar, dissuadir, agradecer. Posteriormente, quando em exercício como primei ro geral da Companhia, escrevia ainda para influir, informar, discordar e pedir ${ }^{16}$. Como assinalou Barthes, identificando na eleição a função dos Exercícios Espirituais: a escrita em Loyola era uma práxis ${ }^{17}$.

\section{LETRAS, INFORM AÇÃO E GOVERNO}

Sob a influência do padre I gnácio a Companhia, desde os primeiros anos, utilizou a escrita como forma predominante de comunicação, ação e registro. Já foi mencionado que no início os jesuítas estavam dispersos pela Itália, I rlanda, Portugal, Espanha, França e depois Ásia. Assim, o objetivo fundamental de qualquer carta era a união dos ânimos em torno da procura da vontade de Deus. Ignácio de Loyola, como primeiro superior geral, teve muito claro que havia de produzir uma imagem da Companhia através das letras.Q ual- 
quer notícia deveria primeiro edificar, e para conseguir a consolação nada melhor que mostrar os avanços da glória divina nas obras e ações apostólicas dos padres e irmãos. Sendo este o objetivo, a missiva não poderia ser deixada ao acaso das impertinências cotidianas dos padres ou à intensidade de seus sentimentos espirituais. Escrevendo para serem lidos por muitos outros, os padres deveriam ter a consciência de que estavam produzindo um texto para ser interpretado elembrado.

Porém superiores, provinciais e o governo geral, precisavam de informações e notícias para tomar decisões relativas ao envio de padres, à abertura de residências,nomeação desuperiores, procura de auxílio de nobres e poderosos, e em muitos casos, correção de desvios e abusos. Sobre isto era urgente escrever mas de forma separada, estabelecendo a diferença entre o produzido para mostrar e edificar e as novidades do complexo cotidiano das casas, eivado de sentimentos que deveriam permanecer reservados aos superiores e interessados. Diferença de texto prescrita por quem fez da identificação de distinção de estados e meios um dos el ementos fundamentais do método dos Exercícios Espirituais.

Entre várias manifestações do santo concernentes a esse entendimento da multiplicidade de textos presentes na correspondência, existe uma carta de dezembro de 1542,escrita para o padre Pedro Fabro, que estava por ordem do papa na Alemanha, na corte de Carlos V. O primeiro companheiro de Iñigo desdeos tempos de Paris se queixava de ter que escrever com freqüência, deixando o santo impaciente pela falta de compreensão da importância das cartas para a Companhia e de suas diversas formas, conteúdos e sentidos. Santo I nácio escreve ao companheiro de forma direta e repetitiva na ênfase de escrever a Roma a cada quinze dias. 0 padre geral distingue aqui o que seria a "carta principal" das "hijuelas".

A "carta principal" deveria ser escrita de tal forma que

(...) se pudiese mostrar a cualquier persona; porque a muchos que nos son bien aficionadosy desan ver nuestras cartas, no las osamos mostrar por no traer ni guardar orden alguna y hal ando de cosas impertinentes en ellas (Loyola,1963, p.649).

Nessa carta principal escrita para provocar edificação em "oidores o lectores", se deveria colocar o que se fazia em sermões, confissões, Exercícios, obras pias. Para que ficasse mais clara a forma de produzir esta carta principal, o santo dizia como el e fazia as suas, narrando as coisas que edificavam:

(...) y despues mirando y corriguiendo, haciendo cuenta que todos la han de ver, torno a escribir o hacer escribir otra vez, porque lo que se escribe es aún mucho mas de mirar que lo que se habla; porque la escritura queda, y da siempre testi- 
monio, y no se puede así bien soldar ni glosar tan facilmente como quando hablamos (Loyola, 1963, p.649).

D esta forma,segundo o santo, escrevendo duas vezes ele se persuadia que as letras fossem "más concertadas y más distintas". Produção do texto com a clareza de seu caráter documental. Ainda para não deixar dúvida,mencionava como refazia a cópia das cartas que recebia de diversas partes antes de enviá-las a outros jesuítas, retirando "lo que es edificación y poner postponer las mismas palabras, cortando e quitando las impertinentes, por daros a todos placer en el senor nuestro y edificación de los que las oyeren de nuevo "(Loyola, 1963, p.650) ${ }^{18}$.

A parece aqui a consciência clara de que nas cartas se produzia a imagem da Companhia para provocar edificação e apoio. Responsabilidade de todos os jesuítas, mas primeiro do padre geral, a quem correspondia distribuir a informação e acertá-la de acordo com o modelo de edificação. Esta procura era o que conduzia o critério para a definição do pertinente. Gestação da escrita encarada como uma montagem definida pel os seus fins e destinatários. Ficava assim em evidência tanto o conhecimento do universo letrado de sua época, ávido que era o santo pelo saber, quanto sua consciência da carta como texto que não podia ser diluído para não ter que "mostrar em partey encubrir em parte" (Loyola, 1963, p.649).

As “hijuelas", por sua vez, não eram meros anexos, embora o santo não as privilegiasse neste texto. Ali seriam colocadas as "otras particularidades impertinentes para la carta principal" como doenças,novas,negócios, podendo "dilatarse em palabras exhortando". D esta forma "en las hijuelas puede cada uno escribir a priesa de la abundancia del corazón concertado o sin concierto; mas en la principal no se sufre, si no va con al gun estudio distinto e edificativo para poderse mostrar e edificar"(Loyola, 1963, p.650). Caberia aqui tudo o que pudesse não edificar, o emocional, o primário, o espontâneo ou sem elaboração e por isso não deveria ser mostrado ou dado a público.

Finalmente o santo, invocando a obediência, dizia que seguiria insistindo nesse ponto e assim rogava e pedia para que "os emendeis em vuestro escribir, preciándoos dello y deseando edificar a vuestros hermanos y a los projimos com vuestras letras" (Loyola,1963, p.650). A edificação ganha assim, neste contexto, um traço de modernidade onde através da escrita se colocava em evidência o real além de uma releitura à luz da experiência de cristianização.

Não precisou Santo Ignácio de todos aqueles rogos, no que dizia respeito a escrever, para com outro companheiro e grande amigo Francisco Xavier. Sintonizad os em muitos aspectos, os dois santos se identificaram também na sua utilização da escrita na Companhia. Francisco Xavier fez também das le tras o seu principal meio de comunicação em relação aos companheiros que 
ficaram na Europa e com os outros missionários que estavam se espal hando pela Ásia. Assim, quando saiu de Goa, em 14 de abril de 1552, deixou instruções ao padre Barzeo, de escrever todos os anos ao padre Ignácio, sobre as novas dosirmãos (Xavier, 1953 , p. 489) "y esto de escribir y recibir cartas hareis com mucha diligência como esto se cumpla" (Xavier, 1953, p. 492). Recomendava, ainda, que se fizessem várias cópias das cartas. Também insistia para quelheescrevessem a M alaca "todoslosaños no faltareis" (Xavier, 1953, p.492), acrescentando que

(...) y sea la carta que vos me escribireis muy cumplida, en que me hagais saber muchas cosas así de las nuevas del estado de la Índia, como del fruto quelos otros religiosos hacen a gloria de Dios y el fruto de las almas (Xavier, 1953, p. 492).

Partindo para tão longe, Francisco Xavier queria se manter a par do que acontecia em Goa tanto no plano do temporal como no avanço da glória de D eus. Queria saber "as novas" e em que condições andava a missão. Q ueria saber, que não era só curiosidade ou fervor missionário, mas também interesse em estar informado para poder participar e intervir com recomendações e comentários. Francisco Xavier se fazia assim presente desde a Ásia com suas cartas e não demorou para que muitos desejassem lê-las e conhecê-las na Europa.

Porém o que a Companhia queria, ou melhor, precisava saber? A esta pergunta feita pelo reitor da casa de formação de Coimbra,padre Urbano Fernandes, respondeu o padre Polanco mandado por padre Inácio, em primeiro de junho de 1551. O secretário do superior geral, diz inicial mente, que isto de escrever aos superiores uma vez por mês não só compreende as novas de edificação e o fruto espiritual em confissões e pregações porque, para isto, basta escrever cada quatro meses, mas o que "nuestro padre desea saber es todo aquello (en cuanto se podrá) que conviene sepa para mas ayudar y mejor satisfazer el cargo que Dios N uestro Señor le ha dado". "Como existen inúmeras coisas das que podem cuidar os superiores locais", continua padre Polanco, "holgaria nuestro padre se le diese información de las co sas que mas importan y de las quetienen mas dificultad"(Loyola,1963, p.766). Como se trata de uma casa de formação, o santo está interessado no modo de proceder dos estudantes, nos seus estudos e na vida espiritual, quem aproveita mais que outros na doutrina e na graça de pregar, "quiénes estan en disposición de ser imbiados por unas partes e outras ya acabado el curso ordinário de sus estúdios" (Loyola, 1963, p.766).

Nas cartas mensais ao su perior, o padre geral deseja saber informações concretas, tais como o número dos que estão na casa ou "quienes entran y se salen o se despiden", como é o cotidiano da formação, quem mostra já sinais 
de poder ser aproveitado em al gum apostolado. Ficando o texto edificante, com os números de confissões e pregações eatos notáveis por conta das cartas principais de cada quatro meses, interessa aqui o importante, o que incidia na vida dos jesuítas ena sua missão, aquilo no qual havia dúvidas ou dificuldades. 0 que supunha selecionar as informações que deveriam ser apresentadas às diversas instâncias da obediência, ponderando sempre às hierarquias superiores. 0 que não foi fácil, a julgar pelas histórias das províncias e pelas vezes em que este tema, presente também nas Constituições, voltou a aparecer nas cartas do fundador, como na célebre "Instrução sobre el modo de tratar o negociar com cualquier superior" de maio de 1555, já comentada aqui (Loyola, 1963, p.923)

Com a importância conferida a estas cartas de mês nas Constituições, como já foi visto, e com o empenho do general em recebê-las e contestá-las através de seu secretário e copistas,se foi constituindo a partir do governo geral, a base de um sistema de informações. 0 que não é de estranhar numa ordem inserida num tempo em que a correspondência, a crônica, o informe se creto, o mapa, os visitadores, faziam parte dos instrumentos de controle e das formas de presença de Estados colonialistas como os da península ibérica, aliás Estados que compunham a base regional da Companhia no século XVI. Ainda que com a precariedade das comunicações da época e com a resistência de não poucos superiores, esse sistema envolvia toda uma estrutura de re gistros, copistas, envios, arquivos, em função de assegurar a comunicação e fornecer ao superior geral e outros superiores os el ementos para suas decisões naquele delicado equilíbrio entre o centralismo e a autonomia, o al to e 0 baixo que constituiu a Companhia de Jesus. Em cartas ou relatórios o jesuíta se comunicava com os superiores distantes informando, consultando, opinando, discordando, assinalando sua disposi ção a obedecer. Era também por cartas que o governo geral, os provinciais e os reitores de colégio transmitiam suas decisões, envios e destinos aos súditos que se encontravam longe.

\section{Francisco XaVier e o modelo da edificaÇÃo nas missões}

Nesse processo de ida e volta na procura da vontade divina, acredito que se foi construindo e definindo nas suas características a missão jesuítica. A presença da Companhia na Europa e em outros continentes envolveu desde 0 começo uma teia de relações e interesses tanto fora como dentro da ordem, que foram determinantes e exigiram grande habilidade para seu gerenciamento a partir do governo central: o serviço ao papa na defesa e expansão da Fé,associação com Estados católicos, com os reis de Portu gal, com o imperador CarlosV e com os reis da Espanha na cristianização das colônias e terri- 
tórios de ultramar. Estabeleceu ainda vínculos com nobres e grandes famílias da I tália e da Espanha de onde provinham vocações, auxílios econômicos, doações, proteção. Com relação à expansão da Companhia fora de Espanha, Portugal, I tália e França, era feita fundamentalmente a partir da presença de padres e irmãos,às vezes os mais qualificados membros destas províncias. Deveriam também ser arbitrados ciúmes e queixas numa mediação entre a obediência e 0 apel o pela disponibilidade que deveria caracterizar o jesuíta. 0 papado, os Estados,os nobres, os padres da Companhia criaram assim expectativas que eram maiores, na medida em que, com obras como os colégios ou com a presença fora da Europa, os jesuítas ficavam em evidência.Estas expectativas deveriam ser satisfeitas tanto na construção e administração de uma imagem, como na direção e características da expansão. No intuito de alcançar estes objetivos, a correspondência foi fartamente utilizada ea produção de textos privilegiada.

N essa teia de expectativas com relação às missões fora da Europa, os jesuítas responderam produzindo um imaginário missionário e criando um método de atuação entre infiéis, ambos se configurando na correspondência entre os padres e irmãos.

O envio de jesuítas à Índia em 1541, presididos por Francisco Xavier, 22 constitui o primeiro grande referente na produção desses dois instrumentos. A partir de sua atuação na Índia, em diversas partes da Ásia até chegar ao Japão em 1549 e morrer em 1552, Francisco Xavier passou a encarnar o missionário, o apóstolo jesuíta por excelência.Essa imagem de Francisco que serviria de modelo a todos os outros missionários da ordem, começou a ser construída ainda em Lisboa com a distinção que ele logo al cançou na corte, recolhida na correspondência dos primeiros jesuítas portugueses e nas suas próprias cartas ${ }^{19}$. Assim, de Goa, Xavier escrevia a santo I gnácio, em outubro de 1542, do sentimento causado entre as crianças que catequizava dizendo que "no me dejaban los muchachos ni rezar mi oficio, ni comer ni dormir, sino que les enseñase al gunas oraciones" (Xavier, 1953, p.108). A figura do dedicado e incansável missionário e dos frutos que produzia no anúncio da Fé católica foi se cristalizando no modelo de edificação que se podia extrair das missões entre infiéis, para ser espalhado nas cortes de Europa e entre os jesuítas. Ao mesmo tempo Xavier se constituiu no primeiro referencial para a definição de um método de atuação da companhia entre infiéis. Consciente de ser o primeiro a estar entre infiéis, quando ainda em Lisboa, antes de partir para a Índia, Xavier pedia a santo I nácio que lhe escrevesse "muy largo" sobre o modo de proceder entre eles e a melhor maneira de servir a Deus "que allá os pareciere que debemos hacer" (Xavier, 1953, p. 76).

A edificação quese podia extrair da atuação missionária equese foi cons- 
truindo nas cartas de Xavier ficou definida pelo componente da conversão no entendimento inaciano. Para a produção da edificação, os reinos da África e da Ásia onde chegavam os missionários, traziam novos cenários definidos pela presença do fiel na frente do infiel. Uma polaridade com traços próprios que tinha como paradigma mais distante o tempo dos apóstolos Pedro ePaulo entre judeus, gregose romanos. Polaridade que só podia ser suprimida pe la produção da conversão e da incorporação à I greja dos novos cristãos.

Como nas composi ções de tempo e lugar das meditações dos Exercícios Espirituais,os cenários das missões presentes nas cartas de Xavier e seus companhei ros são definidos pel os personagen s que neles se localizam e pelas relações assim geradas. No centro o missionário caracterizado pelo seu zelo na sal vação das almas presente nas inúmeras pregações, batismos, confissões e pelos perigos que corre por amor a J esus Cristo. Junto a el e os europeus, principal mente as autoridades coloniais que patrocinam a cristianização e os colonos entre os que se produzem as primeiras reformas de vida movidas pela pregação consoladora ea reconciliação da confissão. À sua frente os infiéis. Os governantes, os interlocutores por excelência, os primeiros a serem contemplados, que são tratados com consider ação e suavidade na esperança que tragam também seus súditos, os homens sábios aos quais se prega para mover suas inteligências em direção à sabedoria divina, as crianças que são facilmente atraídas epara quem sefundam escolas.Finalmenteos homens emulheres adultos,tanto aquel es que se convertem e passam a ser cristãos exemplares, como os que relutam em aceitar o Evangel ho por se prender a seus erros antigos, "pues los grandes ni a malas ni a buenas quieren ir al paraíso", como escreve Xavier, de Goa, a Ignácio, em 1544 (Xavier, 1953, p.137). N ão falta finalmentenestecenário insinuada mais clara,a presença do demônio, o inimigo do gênero humano na linguagem inaciana.

A cristalização de um modelo de edificação missionário centrado nas narrativas da conversão dos infiéis e sua circulação entre os jesuítas e não-jesuítas foi percebida claramente por santo Inácio nos anos cinqüenta, quando escrevendo para o Brasil e para a Índia por intermédio do padre Polanco, alertava sobre o perigo de só escrever cartas de edificação. Como já o tinha feito com os companheiros que atuavam na Europa, o santo dizia a N óbrega, em julho de 1553, que a ele interessava saber "no solamente de cosas de edificación" (Leite, 1954, I , p.512). Também padre Berze, missionário da Índia, Ihe escreve em fevereiro de 1554 dizendo que “Es verdad que para la edificación de las personas de la Compañia lo que toca a los particulares de ella es muy al propósito; pero podria venir de por si" (Loyola, 1963, p.855). Assim, a edificação tão buscada no início dos anos quarenta, já nos cinqüenta estava presente num modelo cristalizado podendo "Venir de por si". 


\section{INÁCIO DE LOYOLA E A REDUÇÃO DO INFIEL}

Como na Europa, a principal preocu pação do superior geral na correspondência com seus súditos nos outros continentes foi a conservação da Companhia ea qualidade e permanência dos frutos produzidos pelos missionários,o que para o padre l gnácio eseus sucessores dependia do aperfeiçoamento do método para atuar entre infiéis. Na instrução ao padre Nuñes enviado em 1555 como patriarca de uma missão à Etiópia pedida por dom João III de Portugal,aparece da própria pena de santo Ignácio alguns dos principais elementos do entendimento da missão entre infiéis.A Etiópia era governada pelo ne gus Cláudio, que para os portugueses descendia do lendário Preste João, de quem se acreditava seria soberano de um reino cristão na Á frica. Na instrução santo I gnácio realça o que chama "ganar el ánimo del Preste" e de "algunas personas grandes". Recomenda que o patriarca deverá utilizar todos os meios honestos para se fazer querer bem do Preste, comunicando sobre a salvação na I greja católica ro mana, acreditando o santo que "en este general, si se le puede persuadir, se ganan muchos particulares, que dél dependen y poco a poco se pueden deducir"( Loyola, 1963, p.910). Como se tratava de um reino cristão que teria caído em erros, deveriam os missionários fazer tomar 24 ciência destes ao Preste.

(...) y al gunos particulares de más autoridad y depués, sin tumulto, siendo estos dipuestos, se mire se podra fazer ayuntamiento de los que más estimados son en dotrina en aquellos reinos; y sin que se les quitase interesse ninguno ni cosa que ellos mucho estimen, hacerles capaces de las verdades católicas y de lo que se de be tener em la Iglesia. (Loyola, 1963, p.911)

Tratava-se pois, de "reducirlos a uniformidad con la I glesia católica", mas sem violência contra os ânimos habituados a outra forma de viver. Recomendava que olhassem os abu sos e desordens que podiam ser reformados suavemente "y em modo que los de la tierra vean claramente que la reformación era necesária, y de aquel los se comience, por que sera gran autoridad para la reformación de otros" (Loyola, 1963, p.913). Para esta reforma

(...) en sus abusos deveria ayudar ademas de los sacramentos la introducción de al gunas fiestas sensibles, como serían procesiones del Cuerpo de Cristo Nuestro Señor, o otras usadas en la I gl esia católica en lugar de sus baptismos, etc; porque aun nuestro vulgo, quees menos grosero, seayuda con esto" (Loyola,1963, p.911).

Pretendendo ainda a conservação católica da Etiópia, acreditava o santo que 
(...) ayudaria mucho para la reducción entre de aquellos reinos,así para los principios como para to do tiempo, que allá en Etiopia hiciesen muchas escuelas de leer y escribir, y otras letras y colegios para instituir la juventud, y tambien los demas que lo habran menester en la leguna latina, y costumbres y doctrina cristiana, que esto seria la salud de aquella nación; porque estos creciendo tendrian afición a lo que al principio hibiesen aprendido, y en lo que le parecería exceder a sus mayores,y en breve caerian y se extinguirián los errores y abusos de los viejos. (Loyola, 1963, p.912)

Todavia, I nácio tratava dos mais variados aspectos, como a formação de intérpretes, os tipos de ornamentos, a presença de livros, a vinda de relíquias de santos, a distribuição de dioceses e o governo do patriarca.

Contando já com os resultados das várias missões fundadas por São Francisco Xavier na Ásia, de posse das informações que chegavam do Brasil, com as Constituições entrando na sua fase final de redação e servindo-se da experiência acumulada no combate dos jesuítas à "heresia” na Alemanha, Santo I gnácio estava em condições de aplicar a um projeto missionário tão peculiar como o da Etiópia, os meios e práticas adotados num percurso espiritual que começava nos Exercícios Espirituais.

Central na espiritualidade inaciana o princípio de que "o bem quanto mais universal mais divino", teve na missão um de seus principais campos de aplicação. Assim, na parte sétima das Constituições, no número 612, com relação ao envio a missões por parte do papa, se deveria escolher os que fossem "convenientes o mas próprios para ello mirando el mayor bien universal" ( Loyola,1963, p.545). No tempo do envio no número 615 também se deveria contemplar " el mayor o menor fructo espiritual que se sintiere hacerse o en otra partese espera, o segun paresciere mas conveniente par al gun bien universal" (Loyola,1963, p.545).Este entendimento do bem universal como mais divino ganhou nas Constituições formulação clara no número 622, ao considerar para o envio lugares e pessoas que, por sua condição, o bem realizado se estenderia a muitos,tanto no caso daqueles considerados grandes, tais como príncipes, prelados,senhores, magistrados, como da mesma forma para com

(...) a person as señal adas em letras y auctoridad, debe tenerse por más de importância, por la mesma razon del bien ser mas universal, pó lo cual también la ayuda quese hiciese a gentes grandes como a lãs Índias, o a prueblos principales - a Univeridades, donde suelen concurrir mas personas, que ayudadas podran ser operários para ayudar a otros, deben preferirse. (Loyola, 1963, p.548)

Vários critérios de escolha para os lugares da presença da Companhia se 
desprendiam desta aplicação do universal à missão: onde houvesse mais necessidade, onde a porta estivesse mais aberta, onde houvesse maior devoção e desejo, onde houvesse mais dívida ou maior perigo "que el enemigo de Cristo nuestro Señor há sembrado cizaña" (Loyola, 1963, p.548).

É nos Exercícios Espirituais que se encontra uma das referências básicas para a justificativa da missão entre infiéis: sua redução à Fé católica para assim salvar sua alma. É também lá que encontramos os principais elementos da forma como os jesuítas deveriam tratar com os infiéis, como era recomendado nas instruções ao patriarca de Etiópia. Na primeira anotação dos Exercícios Espirituais, Santo Inácio os definiu comparando-os com os exercícios corporais de caminhar, passear ou correr, de sorte que todo “modo de preparar o disponer el ánima, para quitar de sí todas las afecciones desordenadas y despues de quitadas para buscar y hallar la voluntad divina se llaman ejercicios espirituales" (Loyola,1963, p.196).A espiritualidade de Ignácio e sua aplicação na salvação das almas estava marcada, pois, pelo reordenamento da vontade, ao entendimento e aos sentidos do ser humano em função da vontade divina. Os Exercíci os Espi rituais deveriam, pois, dispor a pessoa para ouvir e seguir o chamamento do "rei eternal"( Loyola,1963, p.218). Tratava-se, em termosignacianos, de "reconduzir aos fins", isto é, postular ou dirigir os fins almejados pelo homem, de acordo com o que I gnácio de Loyola chamou de princípio ou fundamento ou ainda finalidade primeira de todo ser humano: amar, louvar e servir a Deus e assim salvar sua alma (Loyola,1963, p.203). Estaria na nota 22 que precedia os Exercícios Espi rituais a matriz da redução que se pretendia entre infiéis, quando se recomendava para a relação entre o diretor dos exercícios e o exercitante

(...) presuponer que todo buen Cristiano há de ser mas pronto a salvar la proposición del próximo quea condenarla; y si no la puede salvar, inquira como la entiende, y si mal la entiende, corríjal ecom amor, y si no basta, busque todos los mé dios convenientes para que, bien entendiéndola, se salve.( Loyola,1963, p. 202)

\section{AS INSTRUÇÕES E O MÉTODO MISSIONÁRIO.}

Buscar todos os meios para que o outro entendesse era o grande desafio que apresentava a missão entre infiéis. Porém na prática missionária dos anos cinqüenta e sessenta do século XVI os resultados e o avanço da Fé estavam muito longe dos relatos edificantes. São Francisco Xavier tinha encontrado inúmeros obstáculos na Ásia, principalmente no que ele sonhou como sua grande missão: a introdução do cristianismo no Japão. Em Satzuma teve que 
amargurar a preservação do monopólio religioso por parte dos "bonsos shingon". Em M iyako, capital do império, a Kioto moderna, Xavier suportou injúrias e perseguições ea decepção da indiferença e falta de apoi o dos grandes senhores, os maiores interlocutores no seu método de reduzir à Féz ${ }^{20}$. No Brasil, os índios adultos, preservando os costumes de seus pais, "cierran las orejas para no oir la palabra de salud y converterse al verdadero culto deDios", 0 quelevou então o irmão Anchieta, em junho de 1560, a dizer ao padre geral D iego Laynes que há “tan pocas cosas dignas de se escrivir que no sé que escriva, porquesi espera V.P. que hay muchos de los brasilles convertidos engañarse a sua esperanza" (Leite,1954, III , p.249). Também nas Índias espanholas, onde os jesuítas iniciaram em 1566,uma missão entre osíndios da Flórida, se começou mal, com o assassinato de um dos dois padres. Insistindo em 1568, os trabal hos não produziram os frutos esperados e em 1571 foram assassinados mais missionários ea missão foi abandonada²1.

Assim, embora o teor edificante não tenha desaparecido efetivamente das cartas para "não mostrar", cada vez mais foi prevalecendo na escrita que vinha das missões o envio de consultas dos mais variados temas ea que vinha de Roma,Lisboa ou Espanha a adoção de instruções e determinações do padre geral e dos provinciais sobre as formas da presença jesuítica e o método missionário na Ásia e na América. Durante o mandato do padre Laynes, ele e o secretário Polanco escreveram cartas onde, além de manifestar aos jesuítas do Brasil e da Índia que "tenemos puestos los ojos en vosotros" (Leite, 1954, III , p.9) instruíam sobre várias questões delicadas e urgentes, a maioria delas formuladas a partir de perguntas feitas nas cartas do padre Nóbrega (Lei te,1954, III , p.541). Padre Laynes, em dezembro de 1562, respondia dizendo que pelas cartas recebidas entendeu "la variedad que en el modo de proceder en ciertas cosas, se há tenido en esa província" (Leite, 1954, III , p. 513), e sendo a informação recebida suficiente até o envio de um visitador, resolveu determinar algumas coisas escreven do "lo que me ocurre a al gunos punctos principales de vuestra letra" (Leite,1954, III, p. 513). Aprovou assim, entre outros, o estabelecimento de casas para meninos e meninas do gentio, a seleção de al guns da terra para serem mandados para Portugal, a seleção dos que estavam sendo admitidos à Companhia e ter escravos para tratar das fazendas, do gado epescar para manter as casas que "no lo tengo por inconveniente com que sean justamiente posseídos, lo qual digo porquehe entendido que algunos se hazen esclavos injustamente" (Leite, 1954, III, p. 514).

Situações como estas de pouco ou nenhum consenso entre os missionários, ou polêmicas como os "resgates de índios", as doações deterra, a administração exclusiva dos sacramentos, o destino das esmolas do rei, traziam paraa missão nas colônias uma complexidadequepedia respostas não imaginadas 
nas Constituições. Perguntas que, como dizia Polanco, "porque aca no se sabe lo particular no se puede responder"( Leite,1954, III, p.542), deixando para 0 discernimento e a prudência dos missionários as respostas.Embora como diz Leite,citando ao padre Borja em carta de 1567, em questões de missões todos os padres gerais queriam ajudar (Leite,1954,I , p.56).

Essa aju da do governo central e das províncias da Europa, na medida em que se diversificavam as missões, significou na prática uma maior intervenção, visando ao estabelecimento de um padrão. Esta intervenção se realizou recorrendo ao uso de instruções escritas, utilizadas por santo I gnácio desde os primeiros envios, estabelecendo critérios, procedimentos, normas e meios para a atuação dos jesuítas, queterminaram sendo definitivas para o método missionário ${ }^{22}$. U ma amostra deste espírito que se impunha no clima de dificuldades missionárias nos anos sessenta do século XVI éa Carta de Borja, em 1567, ao provincial do Peru,pad re Portillo, para o aproveitamento do envio de oito jesuítas ao Peru, como resposta aos vinte solicitados por Felipe II. 0 padre geral dispunha nas suas instruções ir a poucas partes,atender primeiro aos já feitos cristãos,cuidando em conservá- los e depois converter os outros "y así, no tengan por cosa expediente discurrir de una en otras partes para convertir gente, com las cuales despues no pueden tener cuenta" (Astrain, 1914, vol II , p. 305), aplicando assim o critério bem inaciano de ganhar pouco a pouco, fortificando o que se ganhou. Também advertia para não se colocar em perigo de vida entre gente não conquistada, "pues não seria útil para el bien común, por la mucha falta que hay de obreros para aquella viña y la dificultad que tenía la Compañía de enviar otros en su lugar"(Astrain, 1914, vol II , p. 306). A essa altura já havia sido assassinado o padre Pedro Martinez na Flórida, e ganhava força uma visão mais realista do que se podia esperar nas Í ndias. Na verdade, nesta ponderada consideração de si tuações se estavam aplicando as Constituições na Parte Sétima número 22:

Asi mismo entre las obras pías de igual importância y priesa y necesidad, habiendo al gunas mas seguras para quien las trata y otras mas peligrosas y algunas que más fácil y brevemente y otras com mas dificultad y com mas largo tiempo se concluirán, las primeras asi mesmo deberán preferirse. (Loyola, 1963, p. 549)

Padre Borja determinava também, que em regiões de índios ainda não conquistadas, os padres fixariam sua residência em lugar seguro como onde residia o governador, proibindo as "salidas peligrosas" mesmo com ordem do superior. Para a entrada nestas regiões se deveria procurar saber que gente

(...) es aquella em que han de aprovechar, que errores y sectas de gentilidad siguen, que inclinaciones y vícios tienen, si hay doctos o personas de crédito entre 
ellos, para que estos se procuren ganar como cabezas de los otros y qué remedios, conformes a estas cosas se les puedan y deban aplicar y com los de más entendimiento procure antes com suavidad de palabras y ejemplo de vida aficionarlos al verdadero camino, que por otros rigores. (Atrain, 1914, vol II, p. 305)

De novo a presença nas instruções missionárias do terceiro padre geral,os traços da espiritual idade inaciana na consideração real dos fins a alcançar, as condições do lugar, os meios. Também aqui o estabelecimento das diferenças e hierarquias entre as gentes e o discernimento sobre as ações mais próprias a serem dirigidas, buscando sempre o mai or bem universal. Ainda a redução entendida como um processo destinado a persuadir, a mover o entendimento para se abrir a Deus. Bases da constituição de um método missionário que espe rava por novos intérpretes como José de Acosta e M atteo Ricci.

\section{CONCLUSÃO}

Ao considerar a produção de cartas no âmbito da construção da missão na Companhia de Jesus no século XVI, se trabalhou aqui numa leitura dessa documentação por parte do historiador. No contexto da espiritualidadedos jesuítas no século XVI, de al guma forma aqui tratada,tanto a missão como 0 que dela se escrevia estava conduzido pela busca da vontade divina. Princípio e fundamento do ser humano e da criação que se realizava na identificação do bem universal como o mais divino. Na proposta de uma ordem gerada em grande parte por ibéricos para servir à I greja no século XVI, o bem universal foi identificado, entre outros, na convocação para trabalhar no anúncio da boa nova aos infiéis da Ásia e da América.

Resgatou-se pois, mesmo que temerariamente, a evidência do texto inaciano nas cartas dos missionários e se lhe colocou numa abrangência que supera o edificante, apontando para uma multiplicidade de sentidos. Isto dentro da proposta que, esse registro, por específico que seja, tem que ser ouvido e interpretado pela análise histórica.

Fundada por al guém que escreveu quase sete mil cartas e composta por letrados, a Companhia de Jesus fez da correspondência o lugar onde ficava visível a "universal Companhia". Gerador de múltiplos textos quando escrevia, Inácio de Loyola transferiu com paciência a seus súditos a consciência da distinção de diversos interlocutores e a elaboração criteriosa da escrita. Nas cartas, os missi onários apareciam como os companheiros de Jesus que queriam,segundo os Exercícios Espirituais,ser colocados ao lado do Cristo pobre e padecer com ele. M as para esse seguimento, os padres precisavam saber o que fazer para al cançar seus fins. As cartas constituíam assim um espaço de 
tensão, de negociação, de recuos e principalmente de ação. Acreditando quea edificação deveria vir por si, se preocupou Loyola principalmente por estabelecer a base do que aqui foi chamado de um sistema de informações destinado a ajudar na tomada de decisões e na realização de ações.

No caso das missões, na cópia e envio de cartas com diversos destinos, foi construído e definido o projeto jesuítico missionário numa troca de informações que se realizava no eixo Roma,Lisboa,Índia, Brasil. Tal projeto foi examinado aqui a partir da procura de um método para levar a boa nova entre infiéis. N essa procura por um método no tempo de Loyola, Laynes e Borja, teria havido um recurso contínuo à matriz inaciana no seu entendimento do bem universal e da redução espiritual e o reordenamento de fins e meios, que se materializou na produção de instruções missionárias queterminaram definindo os rumos da atuação da Companhia fora da Europa.

\section{NOTAS}

* Este trabal ho faz parte de uma pesquisa maior em andamento sobreĺndios e M issionários nos séculos XVI e XVII, que tem contado com a participação de bolsistas do CNPQ. Sou grato ao professor Ênio Brito eLícia Masagão por comentários e correções.

$30{ }^{1}$ Com respeito às cartas da Companhia esuas coleções, ver para o Brasil,LEITE, Serafim. Cartas dos Primeiros J esuítas do Brasil. São Paulo: Comissão do IV Centenário da Cidade de São Paulo, 1954, vol I, p.61 e seguintes.

${ }^{2}$ Para as cartas de Santo I nácio e a Assistência da Espanha, ver a introdução bibliográfica de ASTRAIN , Antonio. H istoria de la Compañia de Jesus en la Asistencia de España. Madrid: Razon y Fé, 1912, vol I p. XIII.

${ }^{3}$ Sobre este trabal ho pioneiro de Capistrano de Abreu, ver as notas de rodapé de José Honório Rodrigues em texto sobre a Historiografia religiosa, que forma partede sua H istória da História do Brasil. Historiografia colonial. São Paulo:Companhia Editora Nacional, 1979, p.256.

${ }^{4} \mathrm{O}$ padre Leite fez isto no marco do que seria a M onumenta Brasiliae S.I. se inscrevendo e seguindo os critérios da gigantesca coleção M onumenta Histórica S.I ., ver LEITE, Serafim, op. cit., vol I, p.69. Ainda LEITE, Serafim tinha editado N ovas Cartas Jesuíticas. São Paulo: Companhia Editora Nacional 1940, publicando depois Cartas do Brasil e mais escritos. Coimbra: 0, 1955.

${ }^{5}$ Entre outros podemos mencionar GADELHA, Regina M aria F. As missões jesuíticas do Itatim. Estruturas socioeconômicas do Paraguai colonial.Séculos, XVI eXVII. Rio de Janeiro: Paz eTerra,1980; BAETA NEVES, Luis Felipe. 0 combate do soldados de Cristo na Terra dos Papagaios. Col onialismo e represão cultural. Rio de Janeiro: Forense,1978;GAM BI N I, Roberto. 0 espel ho do Índio, revisado e reeditado. São Paulo: Axis M undi/Terceiro N ome, 2000;CH AM BO U LEYRO N, Rafael. "Os lavradores de almas", dissertação de mestrado, Departamento de H istória,U SP, 1994;M ASSI M I, M arina. "Descobrimento, ação, conhe- 
cimento e poder no Brasil colonial :estudos históricos psi cológicos", tese de Livre D ocência, Faculdade de Filosofia, Ciências e Letras,U SP, Ribeirão Preto 1995; RAM INELLI, Ronald. Imagens da colonização. A representação do Índio de Caminha a Vieira. Rio de Janeiro: Jorge Zahar Editor, 1996;ASSU N ÇÃO, Paulo. A terra dos brasis: a natureza da América portuguesa vista pelos primeiros jesuítas (1549-1596). São Paulo: Annablume,2000. Para o sul do Brasil, QU EBEDO, Julio. Guerreiros e Jesuítas na U topia do Prata. Bauru:EDUSC, 2000; ainda os doutorados de FLECK, Eliane Cristina D. e M ARTINS, M aria Bohn.

${ }^{6}$ M EIHY, JoséC arlos Sebe Bom. "A presença no Brasil da Companhia de Jesus 1549-1649", tese de D outorado apresentada ao D epartamento de História da U SP em 1975, apontou para a importância de levar em consideração a diferença entre cartas edificantes ecartas informativas.

${ }^{7}$ ASSU N ÇÃO, Paulo. 0 p cit., p.82, diz que com relação às terras americanas era o verbo que melhor definia a ação dos missionários,já que nas colônias nada era digno de ser mantido. Nas cartas de Loyola aquela expressão aparece relacionada a sentimentos de consolação gerados em terceiros por nossas ações em oposição à censura ou rejeição.

${ }^{8} \mathrm{O}$ s trabal hos destes autores viraram livros. Ver KARNAL, Leandro. Teatro da Fé. São Paulo: Hucitec,1998, pp.48-61;ASSU NÇÃO, Paulo. Op. cit., pp. 57-91; QUEBED 0, Julio. Op. cit., pp. 21-48. M inha contribuição é “La experiencia religiosa jesuítica y la crônica dePará y M aranhão em el si glo XVII". In Sandra N egro y Manuel Marzal, Un reino en la frontera. Las misiones jesuíticas en la América colonial, Quito/Lima, A bya-Yala-PUC Peru, 1999.

${ }^{9}$ As Constituições foram redigidas por santo Inácio num processo que foi de 1541 até 1556. A partir de 49, pontos definidos por seis dos primeiros membros, o santo primeiro só e depois com ajuda de seu secretário P. Polanco, foi avançando via consultas a diversos rascunhos e versões em 1547, 1550, até chegar às dez partes de 1556. A respeito ver a introdução ao texto das Constituições do P. I parraguirre em San Ignácio de Loyola, 0 bras Completas. M adrid: BAC,1963, p. 400. Utilizo esta edição das obras completas do santo pela sua fidelidade, trasladando as citações no original.

${ }^{10}$ Para fixar as formas de representação e a obediência, além da chamada carta da obediência aos padres eirmãos de Portugal em março de 1553, Santo I gnácio via padre Polanco, seu secretário, escreveu a "Instrução sobre el modo detratar negociar com cualquier superior" em maio de 1555, onde o ponto quarto diz "Si a la determinación del superior, o lo que a el tocare, replicare alguna cosa que bien le parezca, tornando el superior a determinar, no haya replica ni razones al gunas por entonces" (Loyola,1963, p. 924). Ainda, o santo abria possibilidades de representar com o tempo "porquela experiencia com el tiempo descubre muchas cosas"; isto sem óbice de obedecer.

${ }^{11} \mathrm{H}$ á nas Constituições diversas disposições rel acionadas ao conhecimento e estudo de letras. Aqui é importante mencionar os "Impedimentos para entrar dos que pretendem ser coadjutores espirituais", onde se menciona "Falta de letras o aptitud de ingenio o memória para aprendellas o lengua para explicallas", Constituições, Parte I, cap. 3, oㅡ 183, em O bras Completas de Santo I gnácio de Loyola,. 0 p. cit.,p.454.

${ }^{12}$ Sigo aqui o criterioso estudo de DOM INIQUE BERTRAND, S.J., La politique de Saint Ignace de Loyola. Paris: Lês Editions du Cerf,1985, onde compara numericamente a cor- 
respondência do santo com a de outros contemporâneos,Erasmo 1.980, Lutero 3.141, Calvino .1247, Catarina de M édecis 6.381, entre outros, p.39.

${ }^{13}$ Pelo levantamento feito por DOM IN I QUE BERTRAND, op. cit., Loyola escreveu mil quinhentas e quatorze cartas a não-membros da Companhia, duas cartas ao papa e duas ao imperador, noventa e duas a reis e pessoas da família real, oitenta e duas a grandes nobres europeus, setenta e uma a cardeais, cento e quarenta a altos funcionários e suas famílias, cento e quarenta a bispos e 301 a nobres, etc., p. 42.

${ }^{14} \mathrm{Um}$ bom exemplo é a carta a Felipe, príncipe da Espanha, de fevereiro de 1549 , on de 0 santo manifesta o apreço pelo príncipe herdeiro da Espanha,sem dizer ou pedir nada,mas que tinha sido escrita no contexto de uma visita do contador-mor do príncipe e embaixador extraordinário a Roma, quando se tratou de questões referentes à reforma dos mosteiros em Catalunha, ver, San I gnácio de Loyola, 0 bras Completas, op. cit., p. 715.

${ }^{15}$ BARTHES, Roland. Sade, Fourier, Loyola.. Paris: Éditions Du Seuil, 1971, p. 47.

${ }^{16}$ D ominique Bertrand, na La politique de Saint I gnace de Loyola, op. cit., elaborou uma série de tabel as das categorias das cartas p. 73, dos grandes temas $p .91$, e dos meios sociais aos quais se dirigiu santo Inácio, p.115.

${ }^{17}$ BARTHES, Roland. 0 p cit., p.54.

${ }^{18}$ Este refazer a carta e mexer no seu texto praticado por santo Inácio, foi aprendido e seguido por seu secretário padre Polanco, para desespero dos historiadores, como menciona LEITE, Serafim. Op. cit., vol. I, p.58.

${ }^{19} \mathrm{Ver}$, Cartas e escritos de San Francisco Xavier. M adrid: BAC, 1953.

${ }^{20}$ Para as missões de São Francisco Xavier no Japão, ver LACOUTURE, J ean. Jesuítas I Los conquistadores. Paidos: Barcelona 1991, pp. 206-211.

${ }^{21}$ Para a missão da Florida e o assassinato do padre Pedro M artinez, ver ASTRAIN, Antonio. Op. cit., vol. II, p. 288.

${ }^{22} \mathrm{~N}$ os levantamentos de D ominique Bertrand, santo I nácio teria escrito 90 cartas sobre assuntos de missões. Ver La politique de Saint I gnace de Loyola, op. cit., p.73.Em 24 de setembro de 1549, santo Inácio redigiu uma serie de instruções para os jesuítas que iriam lecionar teologia na universidade de Ingolstadt na Alemanha. D essas instruções constavam o que podia ajudar para al cançar o fim primário, a pureza na Fé e a obediência à Igreja, e o fim secundário de promover a Companhia na Alemanha e os meios comuns para alcançar a ambos. Ver, O bras completas de San I gnácio de Loyola, op. cit., p. 740. 